Technical Paper

액체로켓엔진 연소기 연소안정성 평가시험

안규복 $^{\mathrm{a}, *} \cdot$ 김종규 $^{\mathrm{b}} \cdot$ 최환석 $^{\mathrm{b}}$

\title{
Combustion Stability Rating Test of Liquid Rocket Engine Thrust Chamber
}

\author{
Kyubok Ahn ${ }^{\mathrm{a}, *} \cdot$ Jong-Gyu Kim $^{\mathrm{b}} \cdot$ Hwan-Seok Choi $^{\mathrm{b}}$ \\ a School of Mechanical Engineering, Chungbuk National University, Korea \\ ${ }^{\mathrm{b}}$ Combustion Chamber Department, Korea Aerospace Research Institute, Korea \\ *Corresponding author. E-mail: kbahn@cbnu.ac.kr
}

\begin{abstract}
As a evaluation method of combustion stability in a liquid rocket engine thrust chamber, external disturbance devices are used. In the paper, the study on pulse-gun ignition tests for a combustion stability rating test of a thrust chamber was performed. Charging volume of pulse-guns was determined by confirming the intensities of the pressure waves from the ignition tests in the cold-flow conditions. While using same injector head, combustion instabilities were not encountered during 14 hot-firing tests without pulse-guns but combustion instabilities were triggered by pulse-gun ignition during 2 hot-firing tests. The results showed that the pulse-gun ignition test could be the evaluation method and could reduce the hot-firing test number for the stability rating of a thrust chamber.

$$
\text { 초록 }
$$

액체로켓엔진 연소기의 연소안정성을 평가하기 위한 방법으로 연소 시 외부 교란을 공급하여 안정성 특성을 확인하는 방법이 사용된다. 본 논문에서는 연소기의 연소안정성 평가시험을 위한 펄스건 기폭 시험에 대한 연구를 수행하였다. 비연소조건에서 펄스건 기폭시험을 수행하여 압력파의 강도를 확인함 으로써 펄스건의 장약량을 결정하였다. 동일한 연소기 헤드에서 펄스건이 적용되지 않은 14 번의 연소 시험 동안 연소불안정이 나타나지 않았지만, 펄스건이 적용된 두 번의 탈설계점 조건에서는 연소불안 정 현상이 발생하였다. 이로부터 펄스건을 이용한 기폭시험이 연소안정성 평가의 방법이 될 수 있음을 확인하였으며, 연소안정성 판정을 위한 연소시험 횟수를 줄일 수 있는 방법임을 제시하였다.
\end{abstract}

Key Words: Combustion Stability Rating Test(연소안정성 평가시험), Thrust Chamber(연소기), Pulse-gun(펄스건), Combustion Instability(연소불안정) 


\section{1. 서 론}

연소불안정 문제는 액체로켓 엔진, 램제트 엔 진, 가스터빈 엔진 등의 개발 중에 종종 발생하 여 개발 기간 및 비용을 증가시키는 원인이 된 다[1,2]. 연소불안정은 음향, 진동 등 시스템의 동특성과 연소의 연동에 의해 발생하며, 일반적 으로 압력 섭동과 열방출 섭동의 상관관계를 나 타내는 Rayleigh criterion으로 설명된다. 수십 년 동안의 연구에도 불구하고 연소불안정을 선 제적으로 예측하는 것은 불가능하며, 아직도 많 은 부분을 경험에 의존하여 개발을 진행하게 된 다[3,4]. 액체로켓엔진 연소기의 경우 연소불안정 의 수동제어 방법으로 배플이나 음향공을 사용 하기도 한다[5].

액체로켓엔진 연소기의 연소안정성을 확인하 는 방법으로는 수많은 연소시험을 통하여 자발 적(spontaneous) 연소불안정을 통계적으로 확인 하는 방법과 폭약이나 펄스건(pulse-gun) 등을 이용 임계치 이상의 인위적인 압력 교란을 연소 중에 공급하여 교란의 증폭여부나 감쇠시간을 측정하는 방법이 있다. 후자의 방법은 전자에 비 해 연소기의 연소불안정을 판단하기 위한 연소 시험 횟수를 크게 줄일 수 있는 장점이 있다. 한 국항공우주연구원에서 개발이 수행되었던 30톤 급 연소기의 경우 60초 연소시험이 성공적으로 이루어졌으며, 연소시험 중 연소실 내에서의 압 력 섭동은 연소실 압력 대비 $2.5 \%$ 미만으로 매 우 안정적이었다[6,7]. 또한 펄스건을 이용한 SRT (Stability Rating Test) 연소시험을 설계점 및 탈설계점에서 수행하여 연소안정성을 검증하 였으며, SRT에 의해 유도된 압력파는 수 $\mathrm{ms}$ 내 에 안정적으로 감쇠되었다[8].

Fig. 1의 F-1 엔진 개발 과정을 살펴보면 초기 에는 자발적 연소불안정 현상이 발생하여 연소 기 헤드를 수정하였고, 이후 폭약 테스트(bomb test)에 의해 유발된(triggered) 연소불안정이 발 생하여 분사기 및 배플의 형상을 변화시켰음을 알 수 있다[9]. 이렇듯 미국에서는 F-1 엔진 개발 시점부터 SRT 연소시험을 수행하여 개발 시간을 단축하려 하였음을 알 수 있다. 참고문헌 $[4,10]$ 을

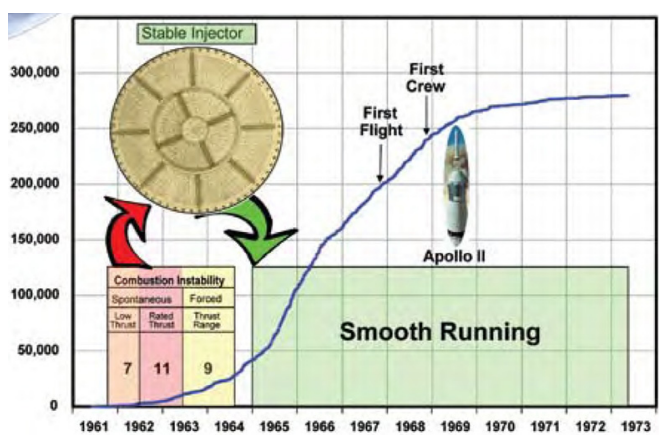

Fig. 1 Development history of F-1 engine.

살펴보면 미국 뿐 아니라 러시아에서도 액체로 켓엔진 개발에서 SRT 시험을 필수적으로 수행하 고 있음을 알 수 있으며, SRT 기폭량 기준 및 감쇠시간(decay time)에 대한 정의를 알 수 있다.

한국형발사체 개발사업을 위해 7톤급 액체로 켓엔진 연소기가 개발 중이며 SRT 연소시험을 진행하고 있다. 본 논문에서는 SRT 연소시험을 위해 수행된 1) 모델 연소실을 이용한 비연소조 건에서의 펄스건 기폭시험 결과를 살펴보고, 2) 펄스건을 이용한 7 톤급 연소기 첫 시제에서의 SRT 연소시험 결과를 살펴봄으로써 액체로켓엔 진 연소기 개발에서 연소안정성 평가시험의 중 요성을 기술하고자 한다.

\section{2. 비연소조건에서의 펄스건 기폭시험}

펄스건을 이용한 SRT 연소시험 전에 펄스건 기폭에 의한 압력파의 강도를 확인하기 위해 모 델 연소실을 이용한 비연소조건에서의 펄스건 기폭시험을 수행하였다. Fig. 2는 펄스건 기폭시 험을 위해 제작된, 7 톤급 연소기와 노즐목까지 동일한 내부 형상을 갖는 모델 연소실이다. 7톤 급 연소기와 동일하게 펄스건 및 동압센서(DP1, $\mathrm{DP} 2$ )를 위치하였으며, 동압센서로는 $\mathrm{PCB}$ 사의 $123 \mathrm{~A} 24$ 모델을 이용하였다. DP1 센서는 펄스건 에 대해 원주방향으로 거의 대칭인 $169^{\circ}$ 에 위치 하며, DP2 센서는 펄스건에 대해 $34^{\circ}$ 에 위치한 다. 횡방향 연소불안정 시 위치별 노드 분포를 측정하기 위해 참고문헌[10]에서와 같이 DP1 센 


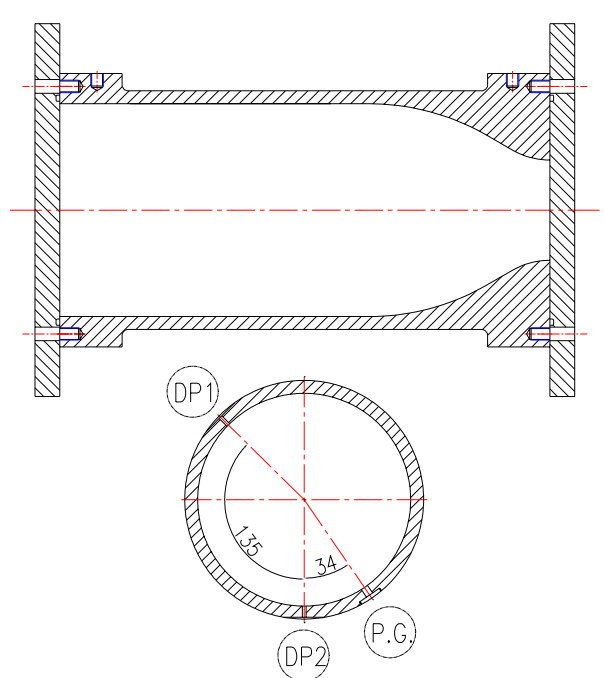

Fig. 2 Model chamber and locations of dynamic pressure sensors and pulse-gun.

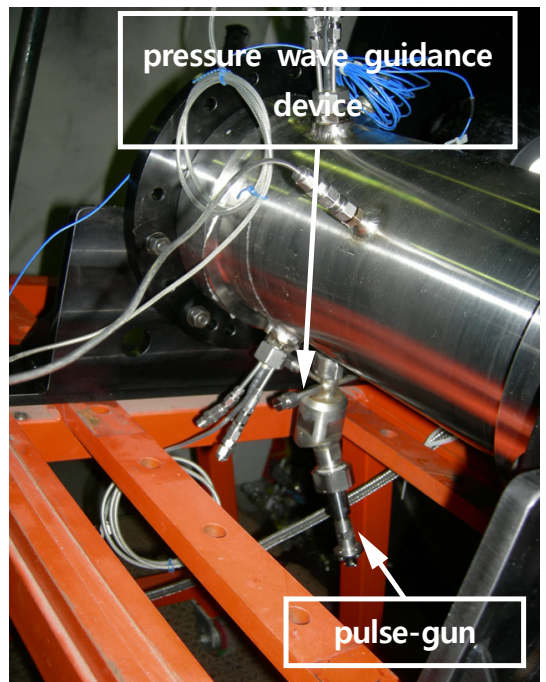

Fig. 3 Pulse-gun with pressure wave guidance device.

서와 DP2 센서는 원주방향으로 $135^{\circ}$ 떨어지게 설치되었다.

모델 연소실을 기체질소를 이용 $70 \mathrm{bar}$ 로 가 압한 상태에서 펄스건 용량을 $600 \mathrm{mg}, 1400 \mathrm{mg}$ 로 바꾸어가며 기폭시험을 수행하였다. 펄스건과 연소실 사이에는 $30^{\circ}$ 압력파 유도장치를 이용하 여 펄스건 기폭에 의해 파쇄된 멤브레인이 연소 실 벽면을 손상시키는 것을 방지하였다(Fig. 3).

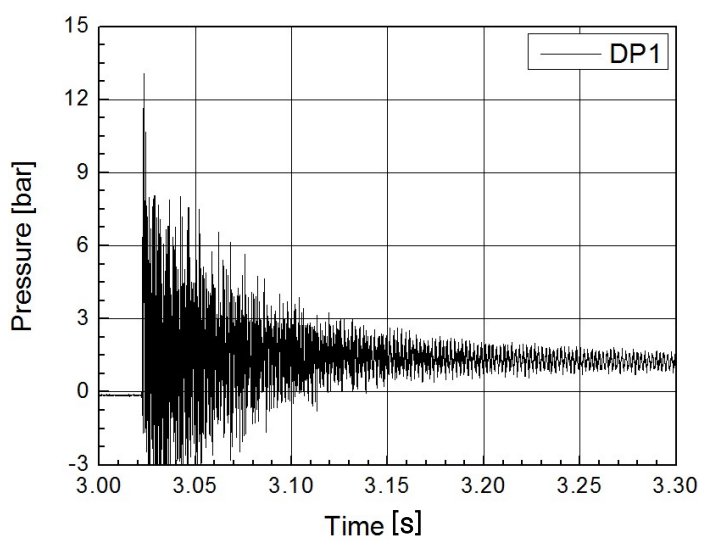

Fig. 4 Dynamic pressure resulting from $600 \mathrm{mg}$ pulse-gun ignition test.

Table 1. Peak value of dynamic pressure resulting from pulse-gun ignition tests.

\begin{tabular}{|l|c|c|}
\hline Pulse-gun capacity & $600 \mathrm{mg}$ & $1400 \mathrm{mg}$ \\
\hline DP1 [raw, bar] & 13.1 & 41.9 \\
\hline DP1* [filtered, bar] & 7.5 & 36.1 \\
\hline DP2 [raw, bar] & 8.4 & 21.8 \\
\hline DP2 $^{*}$ [filtered, bar] & 6.4 & 14.8 \\
\hline
\end{tabular}

* 50 10,000 Hz bandpass filtering

Fig. 4는 $600 \mathrm{mg}$ 펄스건 기폭에 의한 동압 섭 동 결과를 나타내며, 최대 $10 \mathrm{bar}$ 내외의 압력파 가 발생하였다. 비연소조건에서의 펄스건 기폭시 험 결과들을 Table 1 에 정리하였으며, $1400 \mathrm{mg}$ 펄스건이 $600 \mathrm{mg}$ 펄스건에 비해 2 3배 정도 높 은 값을 나타내었다. 7 톤급 연소기 연소시험 동 압 데이터들은 일반적으로 $50 ~ 10,000 \mathrm{~Hz}$ 대역 필터링을 하기 때문에 펄스건 기폭시험도 필터 링 처리된 결과값을 Table 1에 표기하였다.

참고문헌[4]에 의하면 7톤급 연소기 SRT 시험 을 위한 펄스건의 압력파는 $6.4 \mathrm{bar}$ 이상이어야 하며, 참고문헌[10]에 따르면 압력파는 $7 \mathrm{bar}$ 이 상이어야 한다. 이러한 예를 참고해 볼 때 7 톤급 연소기 SRT 연소시험에 $600 \mathrm{mg}$ 용량의 펄스건 을 적용하는 것이 가능하다고 판단되었으며, SRT 연소시험을 위해 $600 \mathrm{mg}$ 과 $1000 \mathrm{mg}$ 의 용 량을 갖는 펄스건을 제작하여 사용하였다. 


\section{SRT 연소시험}

7톤급 연소기에 대한 개념설계는 참고문헌[11] 에 정리되어 있으며, 본 연구에서는 Fig. 5에서 와 같이 노즐 팽창비 1.5 의 단축 노즐을 갖는 연 소기을 사용하여 연소시험을 수행하였다. 연소기 는 크게 헤드부, 1 차 막냉각을 포함하는 실린더 부, 2차 막냉각링, 노즐목부로 구성되며 각 부는 볼트 체결로 한 몸체로 결합된다. 노즐목부 끝단 에서 유입된 케로신은 노즐목부의 냉각채널을 지나 노즐목부 상단에서 튜브를 통해 실린더부 끝단으로 유입되며, 다시 실린더부의 냉각채널을 흐른 후 실린더부 상단에서 배관을 통해 연소기 헤드로 유입되어 와류형 분사기를 통과하면서 연소실 내부로 분사되게 된다.

Fig. 6은 연소시험장에 장착된 연소기의 모습 을 나타내며, 연소시험 중 연소기 내 압력, 온도 및 동압력을 측정하기 위한 센서들이 연소기와 배관에 설치되어 있다.

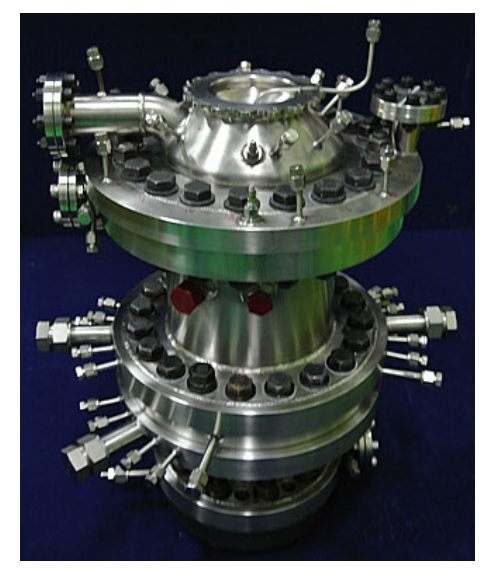

Fig. 5 Thrust chamber with short nozzle.

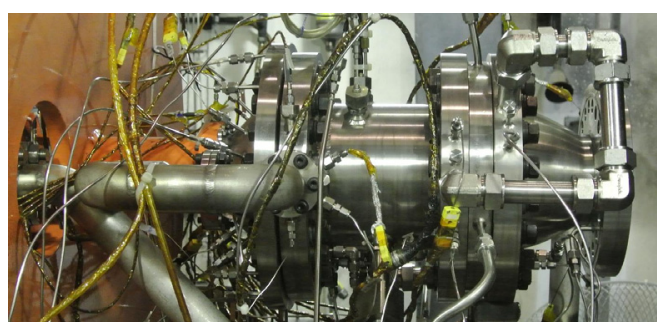

Fig. 6 Thrust chamber installed in the test stand.
본 연구에 사용된 연소기 헤드는 SRT 연소시 험 전 다른 종류의 연소실들과 결합되어 14 번의 연소시험에 사용되었으며 모든 시험에서 연소불 안정이 발생하지 않았다. 본 연구에서 SRT 연소 시험은 세 번 수행 되었으며, 설계점에서 한 번, 설계점에 비해 압력과 혼합비가 낮은 탈설계점 에서 두 번 연소시험이 이루어졌다. 연소기 시험 영역은 엔진의 비행작동 영역에 연소압 $10 \%$, 혼 합비 $5 \%$ 의 여유를 갖도록, 혼합비 2.17 2.76, 연 소압 59.7 81.3 bar 영역의 탈설계점을 갖는다.

\section{1 설계점 SRT 연소시험}

7톤급 연소기의 설계점 조건에서의 연소실 압 력은 $70 \mathrm{bar}$, 혼합비는 2.45이다. 펄스건을 이용 한 SRT 연소시험은 설계점에 근접한 연소실 압 력 70.5 bar, 혼합비 2.36 영역에서 수행되었으 며, $600 \mathrm{mg}$ 펄스건과 $30^{\circ}$ 압력파 유도장치를 이 용하였다. 연소시험은 약 5초 동안 진행되었으며 연소 종료 약 0.5 초 전에 펄스건을 기폭하였다.

설계점 연소시험 시의 시간에 따른 연소실 내 압력 섭동 결과를 Fig. 7에 도시하였다. 펄스건 은 9.8초에 기폭 되었으며, 압력파는 빠르게 감 쇠되어 압력 섭동이 커지는 현상은 나타나지 않 았다. DP1 센서 기준으로 기폭 압력은 필터링 전 $14 \mathrm{bar}$, 필터링 후 $12.3 \mathrm{bar}$ 이며, $\mathrm{DP} 2$ 센서 기준으로는 필터링 전 $9.1 \mathrm{bar}$, 필터링 후 8.5 bar로 계측되었다. 비연소시험과 동일하게 DP1 센서 값이 $\mathrm{DP} 2$ 보다는 높게 계측이 되며, 기존 결과[12]와 동일하게 연소시험 시 계측된 압력파 값이 비연소시험 보다는 높게 나타났다. 연소실 내 압력 섭동의 RMS (Root-Mean-Square) 값은 $0.5 \mathrm{bar}$ 수준으로 연소실 압력 대비 $1 \%$ 미만의 매우 안정적인 연소특성을 보였다.

감쇠시간은 $\mathrm{DP} 1$ 센서 기준으로 $1.3 \mathrm{~ms}, \mathrm{DP} 2$ 센서 기준으로 $0.5 \mathrm{~ms}$ 로 계산되었다. 참고문헌 [4]의 기준에 의하면 SRT 시험에 의한 감쇠시간 은 $15 \mathrm{~ms}$ 이하여야 하며, 참고문헌[10]의 기준으 로 연소실의 1T (first tangential mode)인 4188.6 $\mathrm{Hz}$ 에 대해서 감쇠시간은 $19.3 \mathrm{~ms}$ 이하여야 한 다. 따라서 설계점 조건에서 본 연소기는 연소안 정성 마진을 충분히 갖고 있다고 판단된다. 


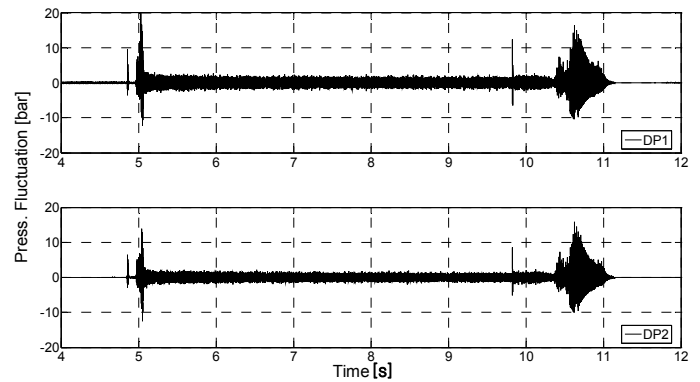

Fig. 7 Filtered dynamic pressure during SRT hot-firing test at design point.

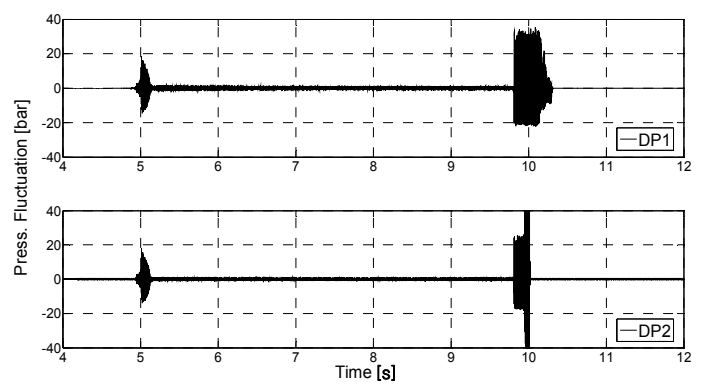

Fig. 8 Filtered dynamic pressure during SRT hot-firing test with $1000 \mathrm{mg}$ pulse-gun.

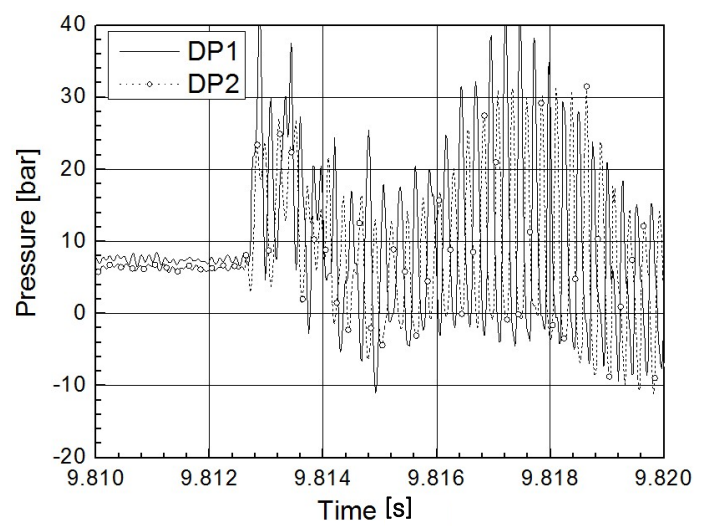

Fig. 9 Raw dynamic pressure during SRT hot-firing test with $1000 \mathrm{mg}$ pulse-gun.

\section{2 탈설계점 SRT 연소시험}

액체로켓엔진 연소기는 엔진이 작동하는 영역 을 포함하는 탈설계점 영역에서 연소성능 및 연 소안정성을 검증해야 한다. 설계점에 비해 연소

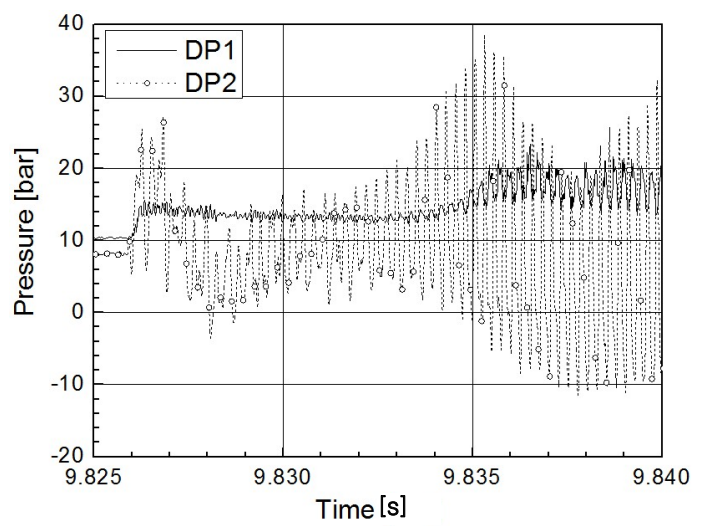

Fig. 10 Raw dynamic pressure during SRT hot-firing test with $600 \mathrm{mg}$ pulse-gun.

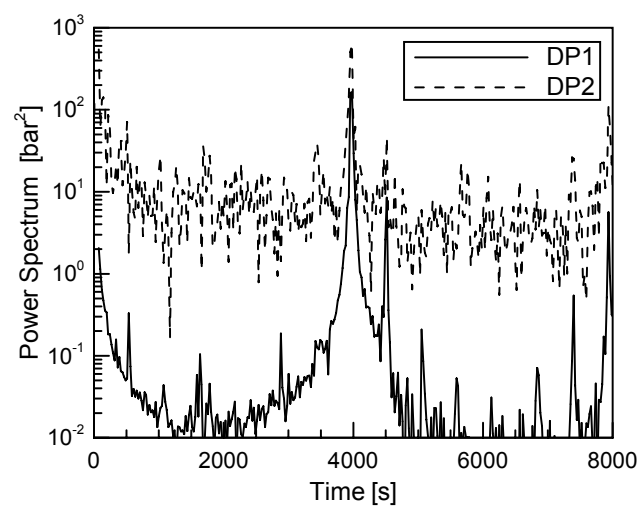

Fig. 11 Power spectrum of dynamic pressure during combustion instability.

실 압력 및 혼합비가 낮은 탈설계점(연소실 압 력: $59.7 \mathrm{bar}$, 혼합비: 2.17)에서 SRT 연소시험을 수행하였다. 탈설계점 첫 번째 SRT 연소시험은 $1000 \mathrm{mg}$ 펄스건과 $30^{\circ}$ 압력파 유도장치를 이용 하였으며, 두 번째 연소시험은 $600 \mathrm{mg}$ 펄스건과 $30^{\circ}$ 압력파 유도장치를 사용하였다. 두 번의 탈 설계점 SRT 연소시험에서 펄스건 기폭에 의해 유도된 연소불안정이 발생하였다. Fig. 8, 9, 10 에서 보는 것과 같이 펄스건 기폭 전까지 안정 적이었던 연소 특성이, 펄스건 기폭 이후 압력파 가 감쇠되지 못하고 연소불안정을 유도하였다.

연소실 내 압력 섭동은 $\pm 25 \mathrm{bar}$ 수준으로 연 소실 압력 대비 $\pm 40 \%$ 의 매우 큰 연소불안정이 발생하였으며, Fig. 8에서 볼 수 있듯이 10초 이 
후 DP2 센서는 손상이 발생하여 계측을 할 수 없었다. DP1 센서 기준으로 압력 섭동의 RMS 값은 $15 \mathrm{bar}$ 내외로 연소실 압력 대비 $21 \%$ 수준 이었다. 연소불안정 시 압력 섭동의 파워스펙트 럼을 Fig. 11에 도시하였으며, 연소기의 $1 \mathrm{~T}$ 모드 에 해당하는 $4000 \mathrm{~Hz}$ 에서 큰 에너지 값을 갖는 것을 알 수 있었다.

앞에서 언급하였듯이 동일한 연소기 헤드를 이용한 17 번의 연소시험이 수행되었다. 펄스건을 적용하지 않은 초기 14 번의 연소시험은 모든 운 영조건을 포함하는 설계점 및 탈설계점에서 수 행되었음에도 연소불안정이 발생하지 않았지만, 펄스건을 이용한 SRT 연소시험에서는 외부 압력 교란이 연소실 압력의 $20 \%$ 정도로 과도하지 않 음에도 두 번 만에 연소불안정이 발생하였다. 이 렇듯이 SRT 연소시험은 설계, 제작된 연소기 시 제의 연소안정성 여부를 빠르게 판단하는데 큰 도움이 되는 것을 알 수 있다.

\section{4. 결 론}

7톤급 연소기 초기 모델을 대상으로 펄스건을 이용한 연소안정성 평가시험을 수행하였다. 설계 점 조건에서는 펄스건 기폭에 의해 연소불안정 현상이 야기되지 않았으나, 연소실 압력과 혼합 비가 낮은 탈설계점 조건에서는 펄스건 압력파 에 의해 연소실의 $1 \mathrm{~T}$ 모드에 해당하는 연소불안 정 현상이 발생하였다. 외부교란 없이 연소기의 연소안정성 마진을 판단하기 위해서는 신뢰성 확보를 위해 무수히 많은 연소시험을 수행해야 하나, 펄스건을 이용한 연소안정성 평가시험을 수행함으로써 설계된 연소기 대한 연소시험 횟 수를 상당히 줄일 수 있음을 확인할 수 있었다.

\section{References}

1. Yang, V. and Anderson, W.E. (eds.), Liquid Rocket Engine Combustion Instability, Vol. 169, Progress in Aeronautics and Astronautics,
AIAA, Washington, D.C., U.S.A., 1995.

2. Lieuwen, T.C. and Yang, V. (eds.), Combustion Instabilities in Gas Turbine Engines: Operational Experience, Fundamental Mechanisms, and Modeling, Vol. 210, Progress in Aeronautics and Astronautics, AIAA, Virginia, U.S.A., 2005.

3. Huzel, D.K. and Huang, D.H. (eds.), Modern Engineering for Design of Liquid-Propellant Rocket Engines, Vol. 147, Progress in Aeronautics and Astronautics, AIAA, Washington, D.C., U.S.A., 1992.

4. Dranovsky, M.L., Combustion Instabilities in Liquid Rocket Engines: Testing and Development Practices in Russia, Vol. 221, Progress in Astronautics and Aeronautics, AIAA, Virginia, U.S.A., 2007.

5. Combs, L.P., Oberg, C.L., Coultas, T.A. and Evers, W.H., "Liquid Rocket Engine Combustion Stabilization Devices," NASA SP-8113, 1974.

6. Han, Y.M., Kim, J.G., Lee, K.J., Lim, B., Ahn, K., Kim, M., Seo, S. and Choi, H.S., "Low Pressure Test Results of Regenerative Cooling Combustion Chamber for 30 tonf-Class Liquid Rocket Engine," Proceedings of the 2009 KSPE Spring Conference, pp. 71-74, 2009.

7. Han, Y.M., Seo, S., Lee, K.J., Kim, J.G., Lim, B., Ahn, K. and Choi, H.S., "Combustion Test of Regenerative Cooling Combustion Chamber with LOx Lead Supply for 30 ton-Class Liquid Rocket Engine," Proceedings of the 2009 KSAS Spring Conference, pp. 680-683, 2009.

8. Ahn, K., Lim, B., Lee, K.J., Han, Y.M. and Choi, H.S., "Combustion Stability Analysis on Hot-firing Test Results of Regenerative Cooling Combustion Chamber," Journal of the Korean Society of Propulsion Engineers, Vol. 13, No. 5, pp. 15-20, 2009. 
9. Fisher, S.C. and Rahman, S.A., Remember the Giants: Apollo Rocket Propulsion Development, NASA, Washington, D.C., U.S.A., 2009.

10. Reardon, F.H., "Combustion Stability Specifications and Verification Procedures for Liquid Propellant Rocket Engines," CPIA Publication 247, 1973.

11. Kim, J., Ahn, K., Joh, M. and Choi, H.S.,
"Concept Design of Combustion Chamber for 7 tonf-class Liquid Rocket Engine," Proceedings of the 2012 KSPE Spring Conference, pp. 454-456, 2012.

12. Lee, K.J., A Study on the High Frequency Combustion Stability of LOx/Kerosene Liquid Rocket Engine Thrust Chamber, Doctoral Thesis, Chungnam National University, Daejeon, Korea, 2010. 